\author{
Barbara Tołłoczko \\ Graduate School for Social Research \\ Polish Academy of Sciences \\ b.tolloczko@gmail.com
}

\title{
The Structure of Relations Among Neighbours in Croatia
}

\begin{abstract}
The article discusses a study carried out by Croatian researchers from the Ivo Pilar Institute of Social Sciences. The research applied the method of face-toface interviews and was conducted between March and May 2014. Its goal was to investigate the structure of local social relations by exploring the frequency and density of interactions between neighbours. The obtained data were analysed according to the demographic and socioeconomic background of the respondents. The article includes a short introduction into the issue of neighbourhood patterns in Croatia, which is described in the context of broader, global changes. After reviewing the research theoretical and methodological assumptions, I present and discuss its findings. The summary suggests some problems and inspirations for further exploration in the matter of neighbourhood relations.
\end{abstract}

Keywords: Croatia, neighbourhood, social relations, cohabitation, locality

( ne way of exploring the issue of neighbourhood is by looking at it through the prism of locality. Such perspective implies focusing on interpersonal relations and everydaycontacts. This micro-level of human cohabitation is the reservoir for specific emotions, relationships and habits. A very important aspect is also space itself. Neighbourhood relations do

This is an Open Access article distributed under the terms of the Creative Commons Attribution 3.0 PL License (creativecommons.org/licenses/by/3.0/pl/), which permits redistribution, commercial and non-commercial, provided that the article is properly cited. (C) The Author(s), 2015

Publisher: Institute of Slavic Studies, Polish Academy of Sciences

Editor in chief: Jolanta Sujecka

Conception and academic editing of this issue: Maciej Falski 
not happen in a vacuum; the shape of space and its boundaries may be of major importance for the character of human interactions. There is also a particular kind of feeling associated with attachment to land and evoked by the sensation of feeling safe within the boundaries of familiar space, especially in the areas of little mobility, where the feeling of being in a safe place is enhanced by the fact that there are few "strangers" and "newcomers." Having close relations with people living nearby is in itself a way of domesticating space.

In Croatian traditional culture, the neighbourhood has always been at the core of community relations and played a very important role, contributing to the comprehensive image of locality. On the level of common knowledge, locality is associated with certain lifestyle in small cities and villages; a lifestyle of people of little mobility, connected to each other and living at the slow pace of regional events. Consequently, relations between neighbours are seen as ones of close and personal nature. But even if we consider Croatia a peripheral country in terms of the socioeconomic divisions of the world, we cannot deny that also in this country, traditional cultural values have been undergoing crucial changes for some time now - and this concerns also relations between people living nearby. Croatian coastal towns, especially the little ones, for a long time avoided joining the tendency to produce higher and bigger residential buildings, but in the 1990s even in those calm places there started to rise multifamily houses that bigger Croatian cities had already been familiar with for a few decades. This has inevitably had a certain impact on the character and shape of local interactions.

Changes within global patterns of dwelling may be regarded as an inevitable repercussion of modern and postmodern transformations in interpersonal contact, which have become more indirect, reserved and rare. Due to technological development we may observe a broad tendency of transferring relations onto subjects that are distant, but thanks to electronic devices and technological possibilities seem actually closer that the person living next door. Particularly important from Croatian perspective seems the issue of the concentration of people in the big cities as this country has been facing the problem of depopulation, both nationally and in particular regions. ${ }^{1}$ Therefore, the question arises of who is left in the rural areas (parents and grandparents?) and who is moving to bigger agglomerations. Different age and socioeconomic groups will engage in different types of relations and thus create certain kinds of cohabitation rules.

Given the expansion of global changes in collective dwelling patterns and the underlying traditional cultural model of having close ties with people

\footnotetext{
Further information on this subject may be found in: Živić, Pokos, \& Turk (2005) or Lajić
} (1986). 
living nearby, it may be said that there is some sort of clash happening in Croatian reality. Looking from a perspective of social relations, there is no one and definite version of what it takes to be a good neighbour: whether it means alienating oneself in the walls of a flat not to bother anyone or on the contrary - having regular gatherings with the neighbours. The two mentioned positions are the poles on the scale filled with an infinite number of possible realisations of the role of a neighbour. No scientific intuition may now explicitly state towards which end Croatian society is heading: is socialising or alienation the modal behaviour and is it at all possible to describe a modal behaviour in terms of neighbour relations?

The nature of contemporary relations between neighbours in Croatia lay at the centre of attention of researchers from the Ivo Pilar Institute of Social Sciences, who between March and May 2014 conducted a research on this subject. The research itself was a part of a vast study entitled the Pilar's Barometer of Croatian Society and its outcomes were described by Goran-Marko Miletić in the text Who is (Still) Socializing with Neighbours? A Contribution to the Analysis of Local Social Relations (Miletić, 2015). The question posed in this title suggest the sort of problem that were investigating. The main focus was put on the shape and structure of social relations on the lowest, micro level. The objective was to see whether local social interactions in Croatia are still an important part of social life and if so, for whom the most.

Before I make an attempt to review the findings of the research, it is necessary to shed some light on the theoretical assumptions of its authors (Miletić, 2015, pp. 99-102). Neighbourhood is identified as the lowest level of local social interactions. It is a space of special importance: between familiar and strange, between safe and uncertain - it is a sphere of mediation and the first arena of exposing oneself when leaving the boundaries of one's own home. Neighbourhood is also valued as a place of belonging and a reference point while navigating through space. Consequently, the definition of the neighbourhood adopted in the research is of double meaning. It is understood as a physical, spatial entity on the one hand, and as a type of social relation that is grounded in certain territory - on the other. The spatial dimension was delineated in a time-relative perspective, as an area of a diameter of about 15-minute walking distance from one's home, which is a determinant used rather commonly in the social sciences. ${ }^{2}$ Defined thus, the boundaries of a neighbourhood may be understood as a "container" of local social relations. Although the issue of neighbourhood is connected to the lowest level of social life and, as it would seem, should be linked with the reality of everyday

2 Miletić makes references to several authors, such as: Jelić and Low Stanić or Kearns and Parkinson; see: Miletić (2015, p. 100). 
life, Miletić makes it clear that researchers focused only on the so-called "objective dimension of social relations with neighbours" (Miletić, 2015, p. 102). This implies focusing solely on the aspects of interactions that can be observed from outside, such as the frequency of meetings or amount of time spent together, which required putting aside problems of such phenomena as perception, meanings and emotions.

As Miletić clarifies, the need for this study stemmed from prior lack of scientific focus on relations between neighbours in Croatia. In this country, the subject of neighbourhood was addressed mainly through the prism of urban planning and quality of living - in both cases with a practical agenda of city managers, state officials or other groups of interests. In contrast, the discussed research had two goals. One was to produce some knowledge on the structure of local social relations. Since little interest had been paid to this problem in Croatia before, this objective may be described as explorative. The second aim was to "[...] test the hypothesis that the structure of local social relations in Croatia [was] related to demographic and socioeconomic characteristics and residential status of actors" (Miletić, 2015, p. 104).

In terms of methodology, in the whole Pilar's Barometer of Croatian Society study the method applied was a questionnaire survey, carried out during face-to-face meetings at the respondents' homes. The sample of 1000 people was chosen based on several formal requirements, such as having a Croatian citizenship and being over 18 years old. The process of sampling was conducted using the multi-stage stratified probability method to imitate the structure of Croatian population, with a focus on variables including sex, age and level of education. Besides such demographic data, taken into consideration during the analysis were also some socioeconomic features, such as the average monthly income per person in certain household. Given our focus on the subject of local relations, a very interesting and important part of the questionnaire was the "residential history" of the respondent: whether she/he had always lived in certain neighbourhood and if no, for how many years had she/he been living there.

The method was based on the Neighbourhood Relations Scale, invented by the Italian researchers Miretta Prezza, Matilde Amici, Tiziana Roberti and Gloria Tedeschi. ${ }^{3}$ In the Croatian research, the main tool was composed of two elements, corresponding to two aspects of local social relations: their frequency and density, both measured on separate subscales. The frequency of social interactions was measured on a scale from 1 ("Never") to 5 ("Every day") and its outcome is presented in the table below.

\footnotetext{
The original research was conducted in Italy and its goal was to explore the sense of community in relation to a certain town or city-quarter, see: Prezza, Amici, Roberti, \& Tedeschi (2001).
} 
Table 1. Neighbourhood Relations Scale

\begin{tabular}{|l|c|c|c|c|c|}
\hline $\begin{array}{l}\text { Subscale 1: Frequency } \\
\text { of interactions with } \\
\text { neighbours }\end{array}$ & Never & Rarely & Sometimes & Often & Every day \\
\hline $\begin{array}{l}\text { 1. Visiting } \\
\text { neighbours in their } \\
\text { home }\end{array}$ & $12,5 \%$ & $28,5 \%$ & $35,1 \%$ & $20,2 \%$ & $3,7 \%$ \\
\hline $\begin{array}{l}\text { 2. Being visited by } \\
\text { neighbours in own } \\
\text { home }\end{array}$ & $10,7 \%$ & $25,5 \%$ & $36,9 \%$ & $23,0 \%$ & $3,9 \%$ \\
\hline $\begin{array}{l}\text { 3. Stop and talk to } \\
\text { neighbours }\end{array}$ & $3,1 \%$ & $8,6 \%$ & $29,4 \%$ & $42,6 \%$ & $16,3 \%$ \\
\hline $\begin{array}{l}\text { 4. Spend time } \\
\text { doing things with } \\
\text { neighbours }\end{array}$ & $23,6 \%$ & $25,5 \%$ & $31,3 \%$ & $16,9 \%$ & $2,7 \%$ \\
\hline $\begin{array}{l}\text { 5. Exchanging } \\
\text { favours with } \\
\text { neighbours }\end{array}$ & $16,5 \%$ & $24,1 \%$ & $37,8 \%$ & $18,2 \%$ & $3,4 \%$ \\
\hline
\end{tabular}

Source: Table 2 in: Miletić (2015, p. 106).

The chosen tool proved to be a successful solution both in terms of gathering the data and analysing it. It is no surprise that questions 1 and 2 ("visiting neighbours in their home" and "being visited by neighbours in own home") bring very similar outcomes, since they are set to explore the same relationships, only from two different perspectives. In both cases the least popular answer was "every day," although the level of almost $4 \%$ still seems like quite a high score, given the fact that according to my own experiences, rarely anyone pays everyday visits even to friends and family members. Altogether, we can see that around $90 \%$ of respondents visit or are visited by their neighbours, with the highest percentage of answers of "sometimes," which in itself is a bit ambiguous a statement, but by placing it on a scale between "often" and "rarely" we get the sense of how the respondents understood this time reference.

As the data reveals, almost $43 \%$ of respondents talk to their neighbours often, around $29 \%$ do it sometimes and $16 \%$ every day. It suggests that a great majority is used to having some conversations with people living nearby and it seems as a chitchat is some sort of habit between neighbours. This, however, cannot be an indication of a general existence of close relations, because the answers to the next question ("spending time doing things with neighbours") tend to be of a more negative character, as the most frequent choices were "sometimes," "rarely" and "never." Such outcome is especially interesting as this question suggests having common activities and maybe 
sharing free time, which would indicate having some closer relations that go beyond sheer neighbourliness or courtesy. An inquiry into whether people living close to one another exchange some favours may be useful to explore the purposive character of interactions. Having no insight into the content of those favours, we may only conclude that the most frequent answer of "sometimes" (38\%) shows that good manners between neighbours still prevail.

The second element of the research tool was aimed to investigate the density of local social relations. This density was explored through asking two open-ended questions: "how many of your neighbours would you have no problem asking to borrow little things?" and "how many of your neighbours do you consider as your friends?". The answers were encoded into the 5-element scale which was also used for examining the frequency of relations. As it was revealed, the difference between friends and neighbours is clear and those two kinds of human relations occur rather separately: around a quarter of respondents declared that they have no friends at all among neighbours and one third answered that they have a few. Similarly reluctant opinions were formulated in the context of hypothetical situation of borrowing small things. Asking for this seemingly tiny favour (which in common knowledge is emblematic of relations between neighbours, for example in the form of "borrowing some salt") would not come easily for respondents, as around $30 \%$ of them declared that they could think of only a few people appropriate for such request, whereas around 13\% answered that they do not have in their neighbourhood even one person of such kind.

As we look at the issue of density through the perspective of whole research, the first thing which attracts our attention is that on the 5-item scale both questions were most frequently answered with the statements encoded as 2 (e.g., "few," "several"), which may suggest some kind of reluctance against the kind of relationship suggested by the questions. Clearly, that the fact that someone lives next door or in and adjacent house does not mean that the relationship with them will be inevitably evolving into friendship. As the results of the frequency portion of research showed, good manners are still in place, but there is no social rule that would bring people together only on the basis of living in one neighbourhood.

Very interesting results were achieved regarding the differentiation of the neighbour relations patterns according to the demographical and socioeconomic background, as well as the residential situation. These results were confronted by the researchers with the outcomes of the aforementioned investigation into the frequency and the density of local social relations (Miletić, 2015, pp. 107-111). What may be relevant for gender studies is that no differences were recorded in attitudes toward the matter depending 
on the gender of the respondents. There was no significant disparity noticed between the answers of the two genders analysed, which may come as a surprise in the paternalistic Croatian society, where male and female social roles are in general mutually separated and clearly defined. Another variable, the age, showed that younger respondents (18-34 years) have more frequent social relations with their neighbours. From the perspective of common knowledge, this is quite surprising, because we may expect that the age group which would socialize with neighbours most frequently would rather be elderly people, accounting for how long they may know one another and the amount of free time they have. What may help to understand this tendency is the outcome of the analysis of the density of relations in accordance to age: the younger responders show the smallest density. We can suspect that they come into contact with neighbours more eagerly, but the nature of those interactions is rather shallow and reserved so that there is no closer relation that would enable asking for favours nor an expectation of establishing a friendship (expressed and confirmed by the act of calling someone a friend).

The only relevant socioeconomic factor turned out to be represented by the level of education. As it was proven, the higher the educational level, the less frequent the local social relations get. In terms of the residential status, what proved important was the size of a building: the more flats there are, the less people tend to socialize. It comes as no surprise comes that, as proven by the research, the longer people live near one another, the more they socialize and this tendency naturally increases with the passing years, as people get to know each other better. The density of social relations is also increasing along with the decreasing amount of monthly income and by the size of the urban area: the biggest cities are the most discouraging for maintaining close relations with people leaving next door.

Based on the featured data, we can expect that the closest and most frequent relations would be tied between neighbours who did not achieve a high educational level nor have a very high income and who have been living for a very long time in single-family houses in a rather small city. This Weberian ideal type finds its confirmation in common knowledge. The habitants of big cities, pursuing their careers and leading busy lives do not have much time, nor probably willingness, to invest in the social relations with their neighbours. Croatia is a country where the contrast between these two patterns of lifestyle is very much noticeable: there are still plenty of people leading their lives in a traditional way and at the same time - more and more people following the rules of modern world.

The results of the research conducted by the Ivo Pilar Institute of Social Sciences proved that there is a diversification observable in terms of 
neighbourhood relations. The structure of such relations takes a particular shape in accordance to several variables, such as level of education, monthly income, age, the size of a city and a building itself, and the number of years people have been living in the same place. Depending on this sort of background people tend to socialize more or less intensively with their neighbours. The outcome of the discussed research once again confirms the diversification of Croatian social reality - its incoherence and differences that occur between regions, generations and social groups. Nonetheless, as Miletić puts it, the important fact is that „[...] neighbouring is a usual form of social interaction for majority of the target population" (Miletić, 2015, p. 97).

What needs to be underlined is the exploratory aspect of conducted study, since earlier little was known about the structure of local social relations. It provides a good background for further investigation of more qualitative nature. The outcome presented in numbers arouses curiosity and begs the question about what more we can learn about neighbour relations, besides their frequency and density. Given that the research was of quantitative nature, the phenomena of perception, meanings and emotions were not in its focus., It would be extremely interesting to see the actual content of the encounters: are they mostly problem-solving meetings or gatherings on a genuinely friendly basis? Do they arise as a way of addressing current issues or from a simple wanting to socialize with particular people that also happen to be neighbours? The character of such visits is definitely worth investigating more in-depth. In the Croatian research, one can sense an underlying supposition of a positive nature that is associated with neighbour encounters, but the problem of negative emotions would be just as interesting. People may go next door in order to ask the neighbours to be more quiet, and neighbour relations may as well take the shape of constant complaints and quarrels. Consequently, interacting with neighbours and talking to them could be solely a result of good manners or a habit of engaging in small-talk.

During a qualitative research we could also concentrate on the cultural patterns of cohabitation, focusing on whether the clash, mentioned at the beginning of this text, is actually happening, and if so - what its consequences and implied meanings are. This problem is related to the issue of inland migrations and the question of transferring ideas: Are the patterns of locality which value neighbourhood relations transferred with a move to the city and into large, multifamily buildings? Do people follow the patterns they learned through socialisation and enculturation and perform them in the new environment? Or are those patterns in a constant process of evolution? The focus of such study may be put not only on the people migrating and the 
present habitants of big cities, but also on the people who have never moved, who have been living their whole lives in one place or a certain area. The ultimate question would be whether neighbourhood relations are generally changing in Croatia, regardless of where one lives.

Questions presented above are just a hint of huge amount of issues that need further investigation. Neighbourhood relations in the case of Croatia proves to be a sphere of social life that serves perfectly for discussing broad changes of lifestyles, cultural patterns and social interactions.

\section{References}

Lajić, I. (1986). Migration and depopulation of Croatian islands: A short demographic account. Migracijske i etničke teme, 2(1), 61-70.

Miletić, G.-M. (2015). Who is (still) socializing with neighbors? A contribution to the analysis of local social relations. Sociologija i prostor, 53(2), 97-115.

Prezza, M., Amici, M., Roberti, T., \& Tedeschi, G. (2001). Sense of community referred to the whole town: Its relations with neighboring, loneliness, life satisfaction, and area of residence. Journal of Community Psychology, 29(1), 29-52. http://doi. org/10.1002/1520-6629(200101)29:1<29::AID-JCOP3>3.0.CO;2-C

Živić, D., Pokos, N., \& Turk, I. (2005). Basic demographic processes in Croatia. Hrvatski geografski glasnik, 67(1), 27-44.

\section{Note}

No conflicts of interest exist.

The article summarizes the work fully supported by the Croatian Science Foundation under the project number 1875 Second Homes and Social Sustainability of Local Communities in Croatia 